Revista de Metalurgia 50(1)

January-March 2014, e005

ISSN-L:0034-8570

doi: http://dx.doi.org/10.3989/revmetalm.005

\title{
Detección de la corrosión por picadura en aceros inoxidables empleando ultrasonidos
}

\author{
Cristina Rodríguez ${ }^{\mathrm{a},}$, María Victoria Biezma $^{\mathrm{b}}$ \\ aDepartamento de Tecnología Electrónica de Sistemas y Automática, Universidad de Cantabria, Av. Los Castros s/n,

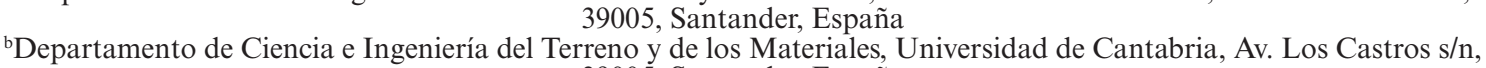 \\ 39005, Santander, España \\ $\bowtie$ Autor para la correspondencia: cristina@teisa.unican.es
}

Enviado: 17 Junio 2013; Aceptado: 29 Diciembre 2013

RESUMEN: Los sistemas pasivables, capaces de desarrollar una capa protectora, delgada, adherente y continua sobre el substrato metálico, presentan excelente resistencia a la corrosión ya que dicha capa se produce instantáneamente al reaccionar con el medio. Ahora bien, en determinadas circunstancias, esa capa se puede romper localmente, dando lugar a uno de los ataques más insidiosos que se conocen, corrosión por picadura, que producen unas condiciones químicas locales que aceleran el proceso corrosivo provocando defectos en el material, tanto externos como internos, con una distribución aleatoria en la superficie metálica. En este trabajo se ha planteado el empleo de técnicas de ensayos no destructivas mediante ultrasonidos para detectar este tipo de ataque en un acero inoxidable austenítico AISI 304, con distinta distribución superficial de defectología y profundidades de ataque, que simulan picaduras, tomando como variable fundamental de la onda ultrasónica la amplitud máxima del eco de fondo.

PALABRAS CLAVE: Acero inoxidable austenítico; Corrosión por picadura; Ensayos no destructivos; Ultrasonidos

Citation / Cómo citar este artículo: Rodríguez, C., Biezma, M ${ }^{a}$ V. (2014) "Detección de la corrosión por picadura en aceros inoxidables empleando ultrasonidos". Rev. Metal. 50(1): e005. http://dx.doi.org/10.3989/revmetalm.005.

SUMMARY: Pitting corrosion detection in stainless steels using ultrasounds. Passive metallic systems are able to develop in a spontaneous way a protective layer on the metallic surface that offers excellent corrosion resistance since really in a physical barrier for the reaction with the environment. However, some factors can break locally this layer, promoting one of the most insidious attack, pitting corrosion, which produces local chemical conditions that favouring the corrosive process causing defects in the material, as externals and internals ones, with a random distribution on the metal surface. In this work, ultrasounds non destructive technique has been employed using as variable the maximum amplitude of the backwall echo in order to detect this type of attack. The material employed is an austenitic stainless steel AISI 304, wherein appear several defectology distributions as superficial such as depths simulating pits.

KEYWORDS: Austenitic stainless steel, Nondestructive testing; Pitting corrosion; Ultrasounds

Copyright: $(C$ CSIC. This is an open-access article distributed under the terms of the Creative Commons AttributionNon Commercial (by-nc) Spain 3.0 License. 


\section{INTRODUCCIÓN}

Los aceros inoxidables tienen numerosas aplicaciones en diversos sectores industriales debido a sus excelentes propiedades mecánicas y de resistencia a la corrosión, además del fácil conformado y su precio competitivo. Sin embargo, la resistencia a corrosión por picadura disminuye notablemente en determinados electrolitos (agua de mar, aguas putrefactas etc.) (Antonya et al., 2010; Bethencourt et al., 2010; Hamzah et al., 2013; Linhardt, 2010; Maier y Frankel, 2010) debido a la rotura local de su capa pasiva protectora; ésta se puede considerar como una alternancia de capas de distinta estequiometría, o bien, como una capa con fuertes gradientes composicionales (Duret-Thual, 2011; Fajardo et al., 2010; Moreno et al., 2011; Pardo et al., 2001). El fenómeno de corrosión por picadura tiene dos etapas, no siempre diferenciadas: una de nucleación y otra de crecimiento, que puede llevar a un agrietamiento del material. Este hecho se puede manifestar entre otros, en fenómenos de Corrosión Bajo Tensión (Hinds et al., 2013; Orlikowsky y Krakowiak, 2013).

La corrosión por picadura la experimentan numerosos sistemas metálicos, entre los que destacan los sistemas metálicos base aluminio, base cobre y base titanio, entre otros, así como distintos aceros inoxidables, mientras que otros sistemas son inmunes, como los sistemas metálicos base berilio. Ejemplos de este problema se pueden observar en un acero inoxidable austenítico AISI 316 AISI 316 empleado en un casquillo en el Puente del Parque de las Llamas de Santander y en la estructura externa del Palacio de Deporte de dicha ciudad (Figura 1). El ambiente, en ambos casos, se puede considerar marino, y las estructuras están bajo la acción predominante del viento del oeste. Cabe resaltar que el agua de mar es un medio sumamente complejo por su composición química y su actividad biológica. En realidad es un electrolito vivo cuyas propiedades cambian constantemente con el tiempo. El pH natural del mar, que oscila entre 7,5 y 8,4 , queda afectado notablemente por las actividades industriales que se desarrollan en zonas costeras y puede generar indirectamente la corrosión por picadura. Los aceros inoxidables además son especialmente susceptibles a las mezclas en donde predominan los aniones tanto cloruros como fluoruros y cloruros, inherentes a determinados sectores industriales, como son plantas de desulfuración, de blanqueo de papel o farmacéuticas. El efecto más notorio se ha observado en una elevación de las relaciones de $\mathrm{Cr} / \mathrm{Fe}, \mathrm{Mo} / \mathrm{Fe}$ y $\mathrm{Ni} / \mathrm{Fe}$ en aceros inoxidables superausteníticos (Mirjalili et al., 2013; Pardo et al., 2001). La despasivación puede ser un estado transitorio en el equilibrio termodinámico del sistema metálico, y considerarse realmente como una etapa de metaestabilidad, ya que algunos sistemas pueden autorrepasivarse.

Para medir la resistencia a la corrosión por picadura de los aceros inoxidables se emplea el índice PREN (Pitting Resistance Equivalent Number) cuya expresión se indica en la ecuación (1).

$$
P R E N=\% C r+3,3 \% M o+16 \% N
$$

Existe una familia de aceros inoxidables, denominados superdúplex e hyperdúplex cuyo PREN es notablemente superior a 38 , considerándose

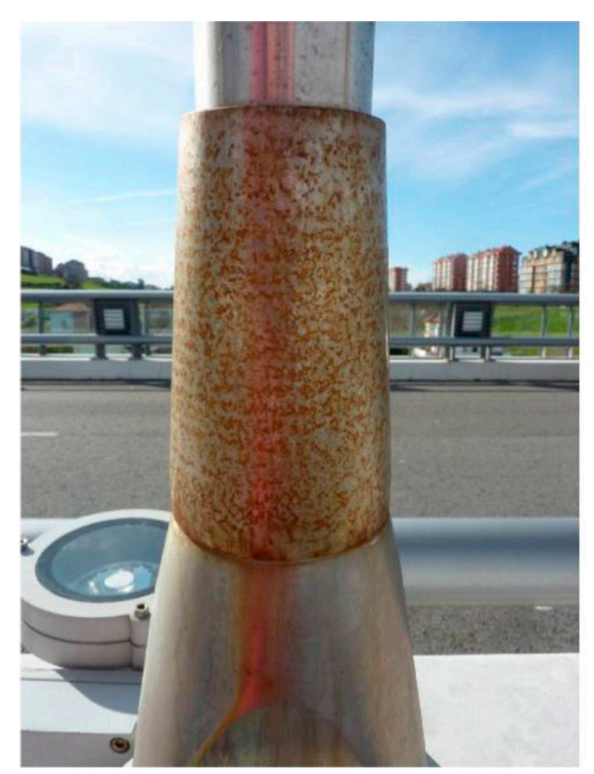

a) Puente del Parque de Las Llamas (Santander)

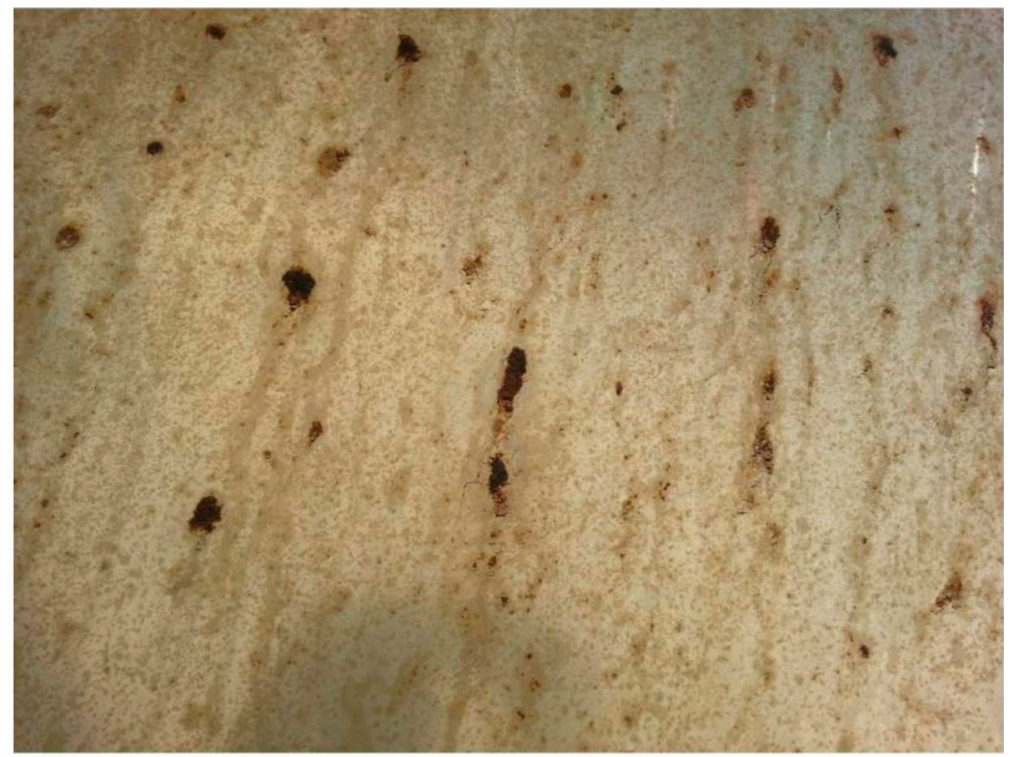

b) Palacio de Deportes (Santander)

Figura 1. Corrosiones por picadura aparecidas en el Puente de Las Llamas y en el Palacio de Deportes de Santander. 
inmunes a corrosión por picadura, y muy empleados en el sector petroquímico (Kim et al., 2011; Tavares et al., 2010), siempre y cuando en su microestructura ferrito-austenítica no aparezca la fase fragilizante sigma (Biezma et al., 2011; Garin et al., 2010). Se suelen utilizar para tubos umbilicales de poco espesor, de las plataformas petrolíferas, en profundidades de hasta 2500 metros en el mar y bajo presiones de $10.34 \cdot 10^{7} \mathrm{~Pa}$ (Shivaraj et al., 2008; www. sandvik.com).

La gravedad de un proceso de corrosión por picadura, viene marcada por la normativa ASTM G4694 (2005). Requiere en primer lugar una inspección visual, precisa, para determinar tanto la densidad de picaduras como su diámetro promedio; ahora bien, para determinar la profundidad de las mismas, hay que recurrir a técnicas destructivas. Los ensayos no destructivos se pueden plantear como una excelente alternativa, para determinar la defectología que aparece en las piezas que poseen corrosión por picadura $y$, en particular, la técnica por ultrasonidos, que permite la inspección in situ (Kraütkramer y Kraütkramer, 1990) es la más empleada dada su diversidad de aplicaciones, sencillez de realización y no necesita de grandes requerimientos de software ni de hardware. Además, permite rapidez en la inspección, obteniendo el resultado de forma inmediata y con una buena fiabilidad, lo que supone una ventaja respecto al empleo de otras técnicas, que tienen que realizarse en laboratorio y, por tanto, económicamente menos rentables. Hay que tener en cuenta que los costos del control de calidad de los materiales repercuten directamente en el costo final del producto y, que en determinados sectores, por ejemplo petroquímico, una falta de conocimiento del tamaño de la defectología presente en sus componentes metálicos puede provocar fallos catastróficos (Shivaraj et al., 2008). Los defectos, tales como corrosión, pérdida de espesor de un componente metálico y picaduras se pueden identificar perfectamente por el cambio de la amplitud de la señal en el tiempo.

Entre las principales ventajas de una inspección ultrasónica destacan las siguientes: tienen una alta sensibilidad, lo que permite la detección de discontinuidades, tanto internas como superficiales, de pequeño tamaño; el análisis de los resultados aporta gran información acerca de la posición y dimensiones de las mismas (Rodríguez, 2012). Asimismo tiene limitaciones que hay que tener en cuenta; una de las más importantes es que requiere de una gran habilidad y entrenamiento del operador para la interpretación de resultados con respecto al requerido con otras técnicas.

Dada la aplicabilidad y efectividad de esta técnica de ensayos no destructivos mediante ultrasonidos en la detección y caracterización de discontinuidades, se va a emplear en este trabajo para revelar la existencia de defectologías que simulan corrosiones por picadura, en un acero inoxidable austenítico AISI 304, con distribuciones al azar en su superficie, y de distinta profundidad y diámetro, utilizando la información extraída de los ecos ultrasónicos. Realmente los defectos de distinto diámetro que se ubican en la superficie se pueden denominar defectos externos, mientras que los que avanzan en el material en profundidad, se pueden considerar como defectos internos. La técnica ultrasónica empleada ha sido mediante contacto directo, para determinar parámetros de estudio, tales como la variación de la amplitud de la onda ultrasónica en función del tiempo de propagación por el material, y estableciendo una comparativa entre el material con defectología y el material libre de defectos (Rodríguez et al., 2006; Rodríguez et al., 2013). El parámetro amplitud de onda es la altura de la onda tomando de referencia un punto que marca la posición de equilibrio en la pantalla del equipo de inspección, que se calcula como la relación entre el valor máximo posible, altura de la pantalla, y el valor que se obtiene en cada punto. Es una magnitud que está directamente relacionada con la intensidad sonora, que se mide en $\mathrm{dB}$.

\section{METODOLOGÍA}

\subsection{Preparación de probetas}

El material utilizado en este trabajo ha sido el acero inoxidable austenítico AISI 304 (UNS S30400), cuya composición química se detalla en la Tabla 1, con un PREN de 18, susceptible de experimentar corrosión por picadura en determinados electrolitos (Fajardo et al., 2010; Mirjalili et al., 2013; Pardo et al., 2001). El diámetro de las picaduras, así como la densidad y la profundidad, aumentará notablemente con el tiempo. Teniendo en cuenta esta problemática, para este trabajo se han fabricado una serie de probetas de acero AISI 304 en forma de discos de $600 \mathrm{~mm}$ de diámetro con distintos espesores, concretamente de 4, 7 y $11 \mathrm{~mm}$. Para cada espesor se elaboraron dos probetas, resultando un total de seis discos para el estudio; en cada uno de ellos, se han inducido tres defectos artificiales, mediante unas inserciones mecanizadas con ayuda de un taladro, que pretende simular diversas picaduras, tal y como se presenta en la Figura 2. Las perforaciones no atraviesan el material, es decir, son defectos ciegos que permiten dejar una de las caras de la probeta libre para la inspección ultrasónica. La decisión de optar por una morfología cónica del defecto se debe al hecho de que, cuando se produce un ataque por corrosión por picadura, ésta no evoluciona en el material hacia el interior de forma lineal, sino formando una especie de curva, por lo que, al buscar la semejanza de un defecto artificial con una corrosión real, es más apropiado proporcionar dicha forma al defecto. Estudios previos han 
TABLA 1. Composición química del acero AISI 304

\begin{tabular}{|c|c|c|c|c|c|c|c|c|c|}
\hline \multicolumn{2}{|c|}{$\begin{array}{l}\text { Designación internacional } \\
\text { para el acero }\end{array}$} & \multicolumn{8}{|c|}{ Composición química (\% peso) } \\
\hline EN & ASTM & $\mathbf{C}$ & Mn & $\mathbf{P}$ & $\mathrm{S}$ & $\mathrm{Si}$ & $\mathrm{Cr}$ & $\mathbf{N i}$ & $\mathrm{Fe}$ \\
\hline 1.4301 & S30400 & 0,08 & 2,00 & 0,04 & 0,03 & 0,75 & 18,0 & 8,0 & Balance \\
\hline
\end{tabular}

corroborado esta morfología (Hamzah et al., 2013; Hastuty et al., 2010; Szklarska-Smialowska, 1972). Por ejemplo, en la Figura 3, se puede observar la corrosión por picadura con una distribución lineal una vez se han eliminado los productos de corrosión superficiales.

La distribución seleccionada para los defectos ha sido aleatoria y distinta para cada espesor: una denominada lineal, tomando de referencia la ordenación de los defectos a lo largo del diámetro del disco, y la otra denominada aleatoria como tal, tomando de referencia la ordenación de los defectos a una cierta distancia del centro del disco. Las variables utilizadas para el estudio de la inspección ultrasónica han sido, de esta forma, el espesor de la pieza a inspeccionar, el diámetro externo de la inserción y su profundidad, cuyos valores seleccionados pueden verse en la Tabla 2. Los defectos se denominan pequeño, mediano y grande en función de su diámetro externo: 3,$5 ; 5$ y $7 \mathrm{~mm}$ respectivamente. A la hora de realizar la inspección ultrasónica de las probetas hay que tener en cuenta que, debido al conformado de las mismas, los espesores reales difieren de las medidas seleccionadas inicialmente. Estos valores se indican también en la Tabla 2. Cabe resaltar que

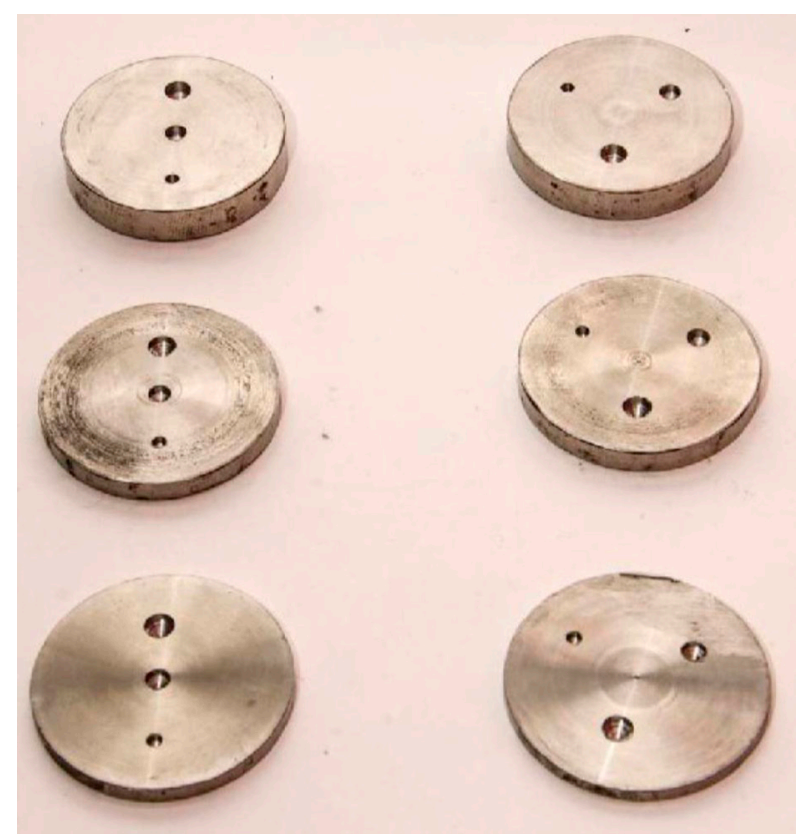

FIGURA 2. Probetas utilizadas en el estudio. durante el proceso de manufactura del acero, o bien por procesos de manipulación, condiciones de servicio, etc., cambia la condición superficial de las mismas (Fig. 4a). Además, debido al reducido espesor de los discos, en alguna ocasión ha aparecido alguna protuberancia en la cara contraria a la de acceso del taladro. Las irregularidades aparecidas pueden observarse en la Figura 4b y, posteriormente, se analizará su efecto en la inspección ultrasónica, pues ambas casuísticas pueden darse en servicio (manipulación de la pieza que destruya localmente la capa protectora, manufactura inadecuada, etc.)

\subsection{Captura y procesado de los datos}

Un sistema de ultrasonido convencional consiste en un único palpador piezoeléctrico que genera una onda ultrasónica. La técnica más común es la de pulso-eco, fundamentada en el efecto eco que produce el ultrasonido cuando, al propagarse en el material, provoca reflexiones en todos los puntos donde existe cualquier tipo de discontinuidad o interfase entre medios y que se observan en la onda reflejada, que es la que aporta información útil acerca de las características de las discontinuidades detectadas. Para visualizar y capturar los ecos ultrasónicos se ha utilizado el equipo USLT2000 de Krautkramer, que nos informa de la envolvente

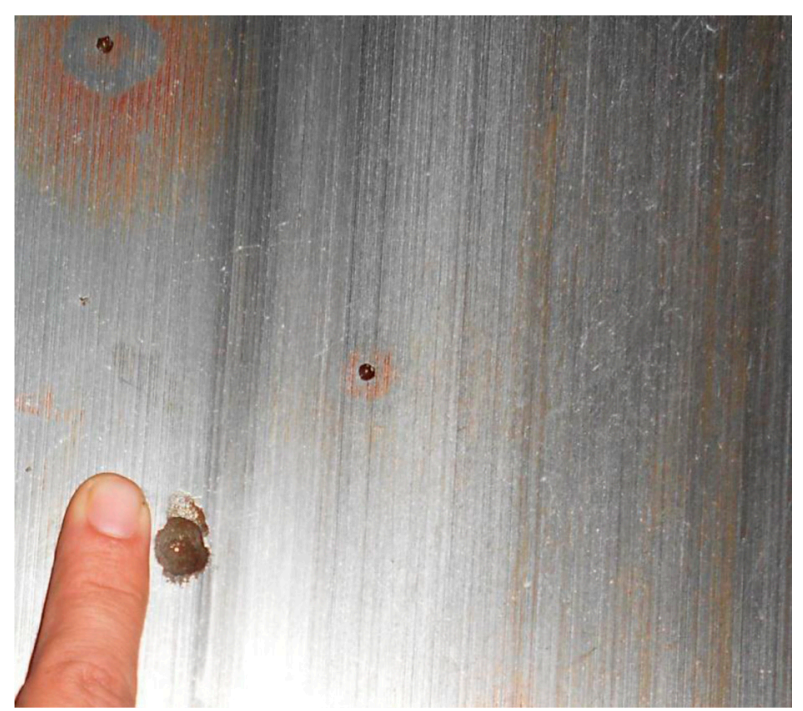

Figura 3. Ejemplo real de corrosión por picadura con distribución lineal. 
TABla 2. Dimensiones de las probetas

\begin{tabular}{|c|c|c|c|c|}
\hline \multirow[b]{2}{*}{ Espesor teórico $(\mathrm{mm})$} & \multicolumn{2}{|c|}{ Espesor real (mm) } & \multicolumn{2}{|c|}{ Dimensiones de la picadura } \\
\hline & Distribución lineal & Distribución aleatoria & Diámetro externo (mm) & Profundidad (mm) \\
\hline & & & 3,5 & 2,9 \\
\hline \multirow[t]{3}{*}{4} & 4,4 & 3,95 & 5,5 & 3 \\
\hline & & & 7 & 3,8 \\
\hline & & & 3,5 & 3 \\
\hline \multirow[t]{3}{*}{7} & 7 & 6,5 & 5,5 & 3,5 \\
\hline & & & 7 & 4 \\
\hline & & & 3,5 & 3,6 \\
\hline \multirow[t]{2}{*}{11} & 11,45 & 10,6 & 5,5 & 4 \\
\hline & & & 7 & 5,2 \\
\hline
\end{tabular}

de los ecopulsos procedentes de las piezas objeto de estudio. Este es un equipo de exploración ultrasónica instalado en un PC portátil, que permite la representación de las señales ultrasónicas, como exploraciones de tipo A, con la que se muestran los valores de amplitud de la onda ultrasónica reflejada por el material en función del tiempo. Esta representación se obtiene con una alta velocidad de actualización, por lo que se visualizan las señales en tiempo real. El sensor ultrasónico empleado en las medidas corresponde al modelo MSEB-4E de Krautkramer. Es un palpador de contacto de incidencia normal, de doble cristal (emisor-receptor), con una frecuencia nominal de $4 \mathrm{MHz}$. La selección de este tipo de palpador se debe a que es adecuado para inspeccionar piezas con superficies paralelas, aplicable a problemas de defectología, metrología y caracterización y a que, por ser de doble cristal, evita la visualización del eco de emisión con lo que desaparece la zona muerta del palpador, aumentando la resolución superficial de la inspección.
Según este método el palpador se sitúa sobre la superficie de la pieza a examinar aplicando además, entre palpador y pieza, un acoplante para favorecer la transmisión de las ondas ultrasónicas en el material. En este caso se ha utilizado como medio acoplante el gel ZG-F de Krautkramer. Además, para realizar correctamente la inspección, se ha de ejercer una presión constante sobre el palpador cuando éste se mueve a través de la superficie. Antes de comenzar a realizar las capturas, se debe calibrar el equipo de medida para seleccionar la velocidad de propagación del ultrasonido en el material objeto de estudio, para lo cual se ha utilizado un bloque de calibración en forma de escalera del mismo material que se está examinando, obteniéndose una velocidad de $5920 \mathrm{~m} \mathrm{~s}^{-1}$ para el acero AISI 304. También se debe realizar un ajuste del sensor para que, en la pantalla donde se obtiene la representación tipo A del eco ultrasónico, se haga coincidir el eco de fondo de la pieza con la profundidad de la misma, en este caso, el espesor de cada probeta.

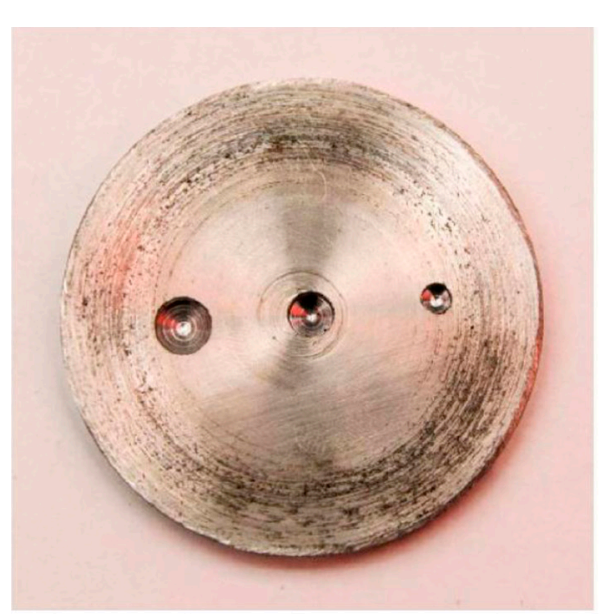

a) Condición superficial

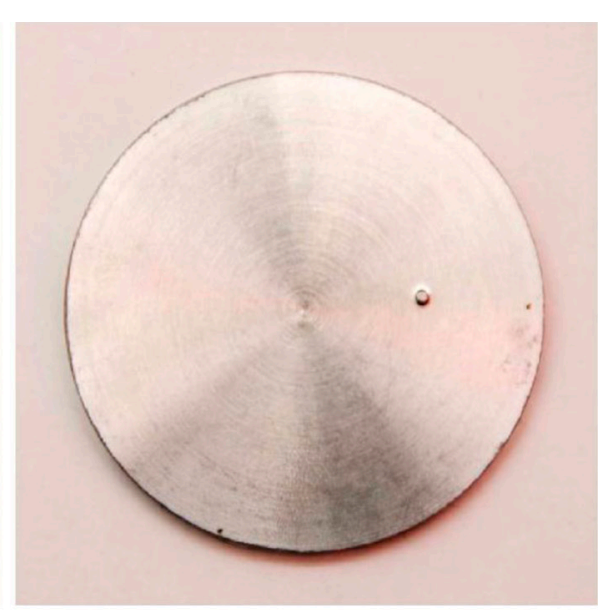

b) Protuberancia

FIgURA 4. Irregularidades aparecidas durante el proceso de manufactura de las probetas. 


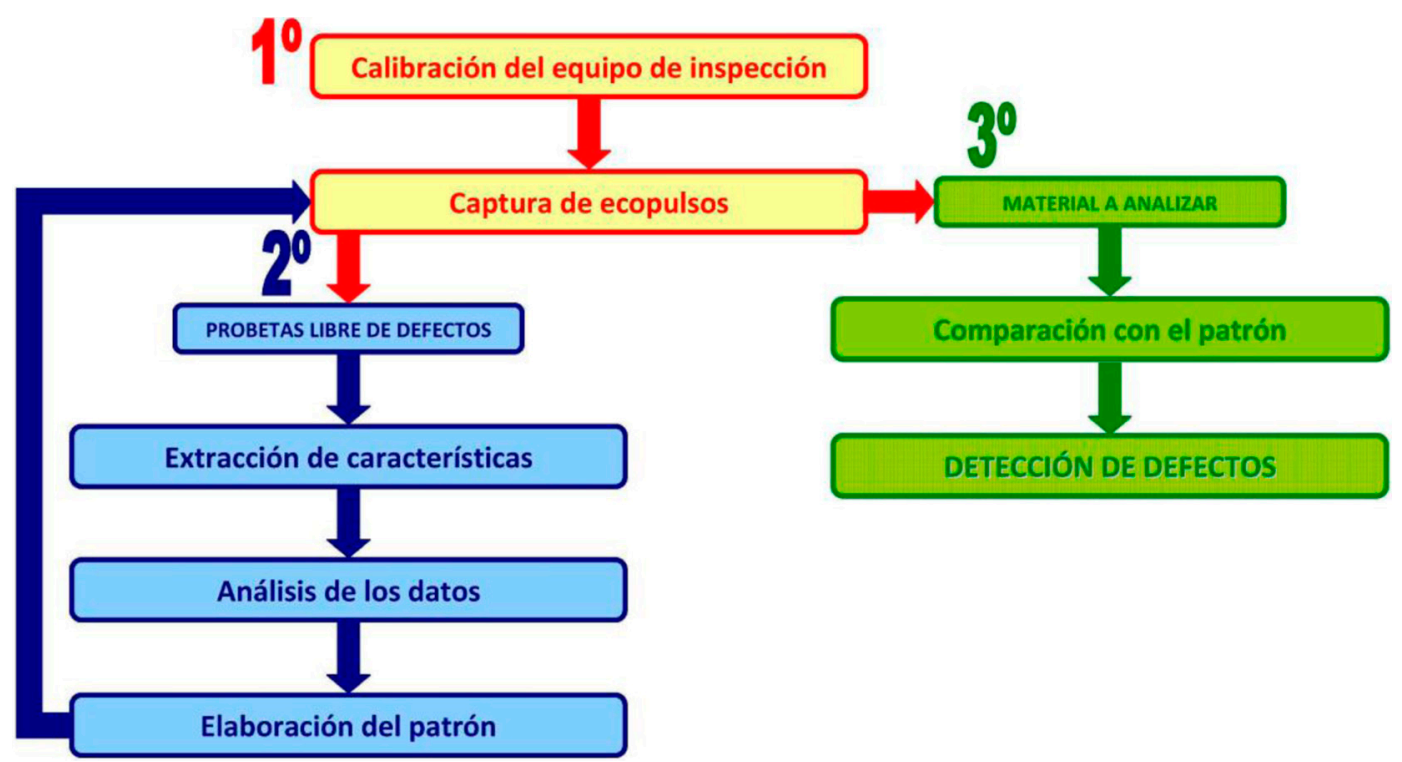

Figura 5. Etapas seguidas durante el estudio realizado en este trabajo.

Una vez calibrado el equipo, el siguiente paso ha consistido en capturar los ecopulsos procedentes de cada una de las piezas; para ello se sitúa el palpador sobre la superficie de la probeta, tanto en las zonas con defectos como en zonas libres de defectos. Para cada probeta se han realizado 40 capturas: 10 ecopulsos por cada heterogeneidad, por tanto 30 ecopulsos en zonas con defectos y 10 ecopulsos en las zonas sin defectos. Con todos los ecos capturados de zonas sin defectos, se obtiene la media, que es la que se considerará como referencia comparativa para el presente estudio. En cada punto seleccionado se captura la señal ultrasónica reflejada por el material, almacenándose los valores de la amplitud en una base de datos de Access. Una vez finalizada la captura de datos, éstos se exportan para realizar su procesado con el software matemático Matlab. En este punto los valores de amplitud de los ecopulsos se almacenan en forma de vector para extraer información de los mismos.

En primer lugar, de los ecos ultrasónicos capturados de piezas libres de defectos se extraen una serie de características que los puedan singularizar y que se utilizarán como patrón para la detección de defectos. A continuación se calculan, para los ecos ultrasónicos capturados de las piezas examinadas, los valores de las características consideradas. Por último, se analizan los resultados para que, aplicando técnicas de reconocimiento con ayuda del software matemático Matlab (Gosálbez et al., 2005), se clasifiquen los ecos según tengan o no defectos (Sambath et al., 2011). Esta clasificación es lo más importante del proceso pues, según los resultados obtenidos, se determinará si la pieza está en perfectas condiciones de su uso, antes de ponerla en servicio, o una vez que está desarrollando su actividad para la que fue seleccionada, tiene zonas que deban repararse para mantener la integridad del material.

Previamente al análisis de resultados, se realiza la media aritmética de las amplitudes de las señales ultrasónicas capturadas en cada posición, para compensar errores en la realización de las medidas. En la Figura 5 se presentan recogidas todas las etapas que se han seguido en el desarrollo del presente estudio, que se resumen en tres pasos principales: la calibración del equipo de inspección, la elaboración del patrón y, por último, la detección de defectos.

\section{RESULTADOS Y ANÁLISIS}

En este apartado se presentan los resultados obtenidos con el empleo de las señales ultrasónicas reflejadas, considerando las variables previamente mencionadas, esto es, para cada espesor de probeta se han tenido en cuenta la distribución tanto aleatoria como lineal de los defectos, lo que permitirá realizar un análisis exhaustivo de dichos resultados. Asimismo se ha considerado, para cada caso, la señal ultrasónica del material libre de defectos y las que se obtienen de los distintos defectos: pequeño, mediano y grande, que tienen diámetro externo de 3,$5 ; 5,5$ y $7 \mathrm{~mm}$ respectivamente.

En las Figuras 6, 7 y 8, se han representado los ecos ultrasónicos reflejados en las probetas de 4, 7 y $11 \mathrm{~mm}$ de espesor, respectivamente. En dichas figuras se observa que, en la mayoría de los casos, a medida que aumenta el tamaño del diámetro, aumenta el valor de la amplitud máxima del eco de fondo, y esta diferencia es más acusada en los defectos de ordenación o tipo lineal respecto a los aleatorios. Ahora bien, tanto para el defecto mediano como para el defecto grande, no existe ninguna influencia de la 


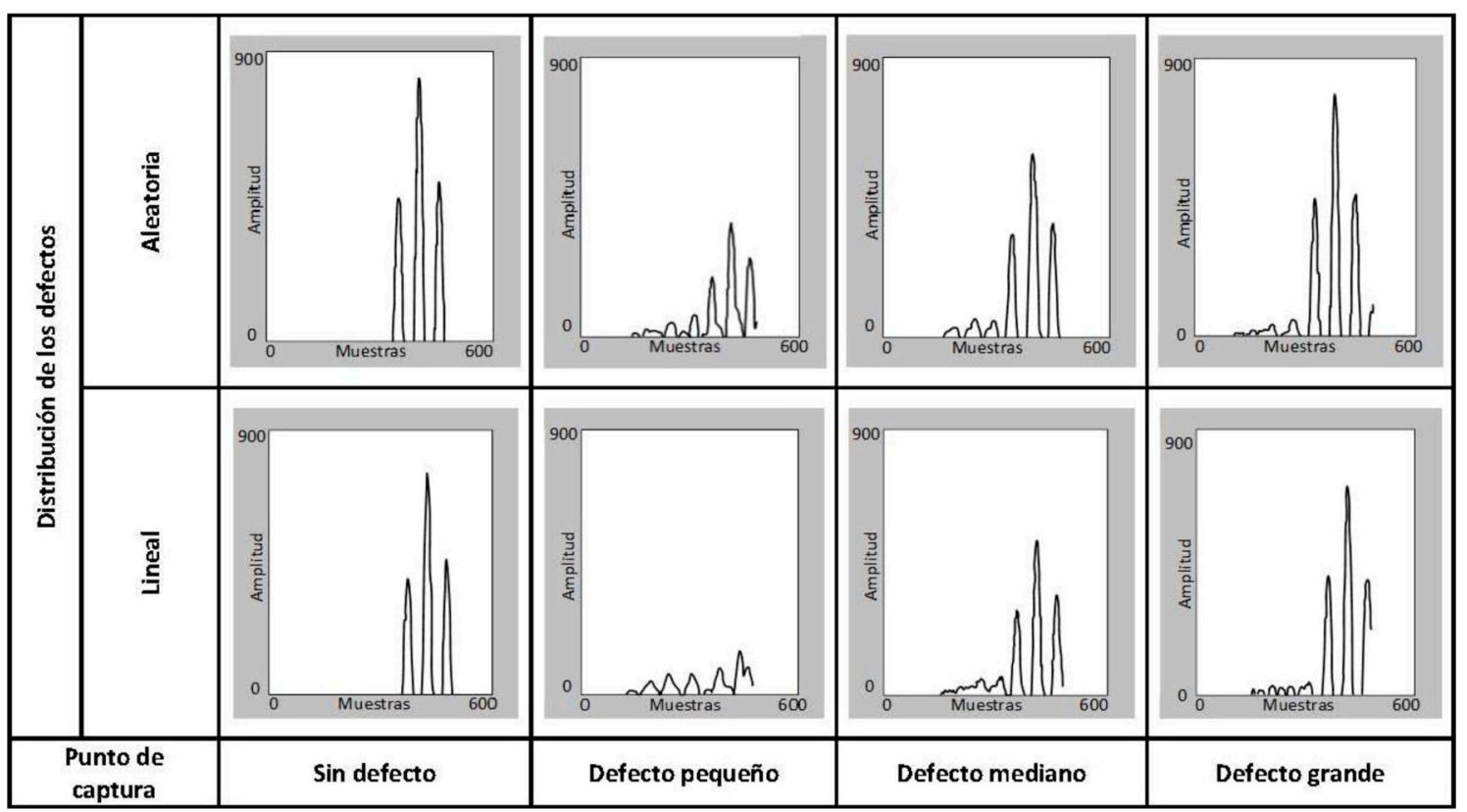

Figura 6. Señales ultrasónicas obtenidas en la probeta de $4 \mathrm{~mm}$ de espesor.

ubicación superficial del defecto sobre la señal ultrasónica obtenida, pues en ambos casos se obtienen valores similares aunque, para los defectos distribuidos de forma aleatoria se produce un ligero aumento de amplitud, cercano al 12\%. Esta tendencia no se verifica en todos los casos como, por ejemplo, en la probeta de $7 \mathrm{~mm}$ de espesor con los defectos centrados linealmente y en la probeta de $11 \mathrm{~mm}$ de espesor, con defectos aleatorios (Fig. 7 y Fig. 8). Esto es debido a que la superficie de las piezas no está en condiciones que favorezcan el apoyo óptimo del palpador, presencia de protuberancias por ejemplo, con lo cual, no se produce una buena transmisión del ultrasonido generado en el material. Además, el acabado de las heterogeneidades, por su morfología cónica, similares a los que se pueden encontrar en casos reales, provoca que la recepción de los pulsos difiera de lo esperado en casos ideales. Esto dificulta en gran medida la captura ultrasónica produciendo, en la señal reflejada, multiplicidad de ecos. Estos casos aislados obstaculizan la interpretación de los resultados y su posterior análisis comparativo,

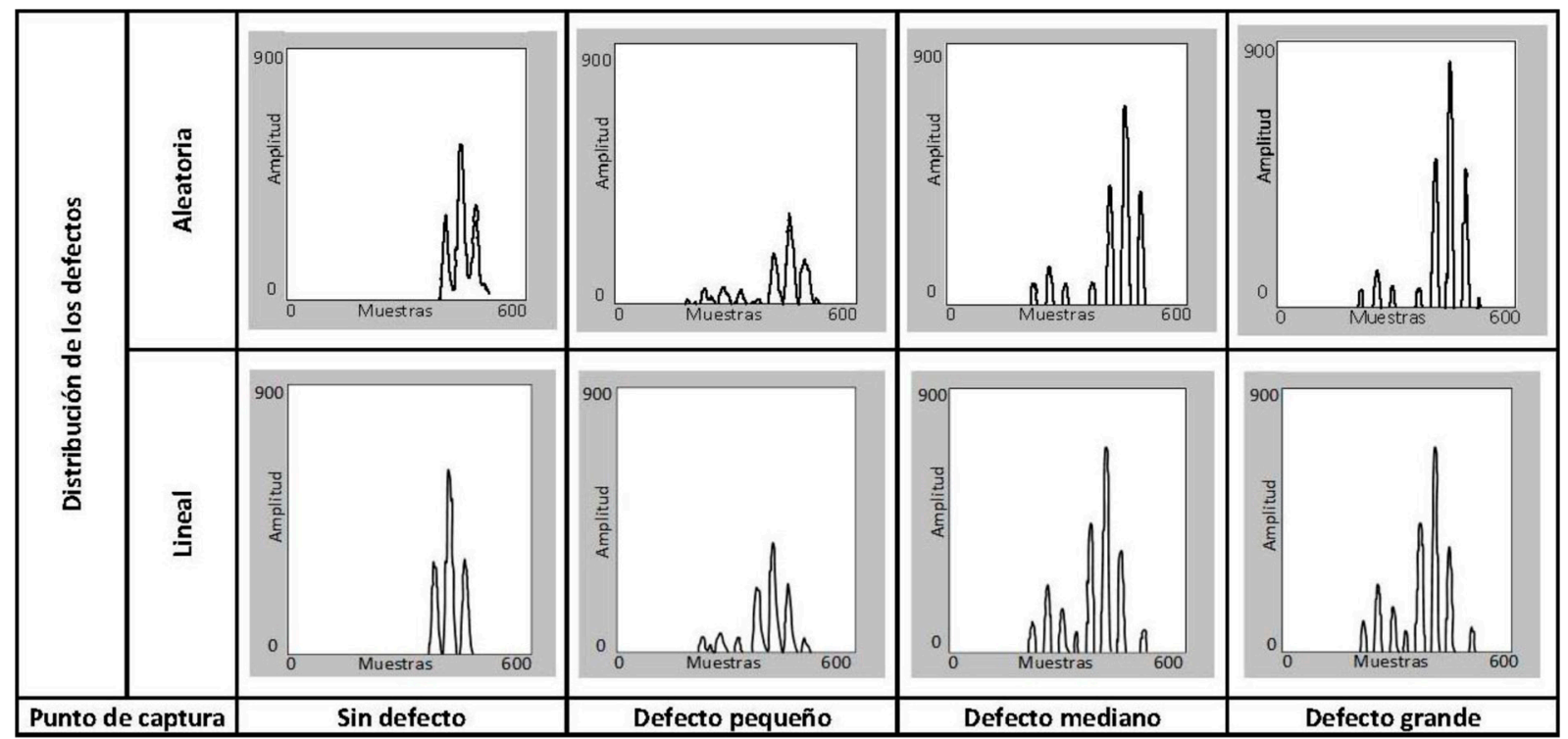

Figura 7. Señales ultrasónicas obtenidas en la probeta de $7 \mathrm{~mm}$ de espesor. 


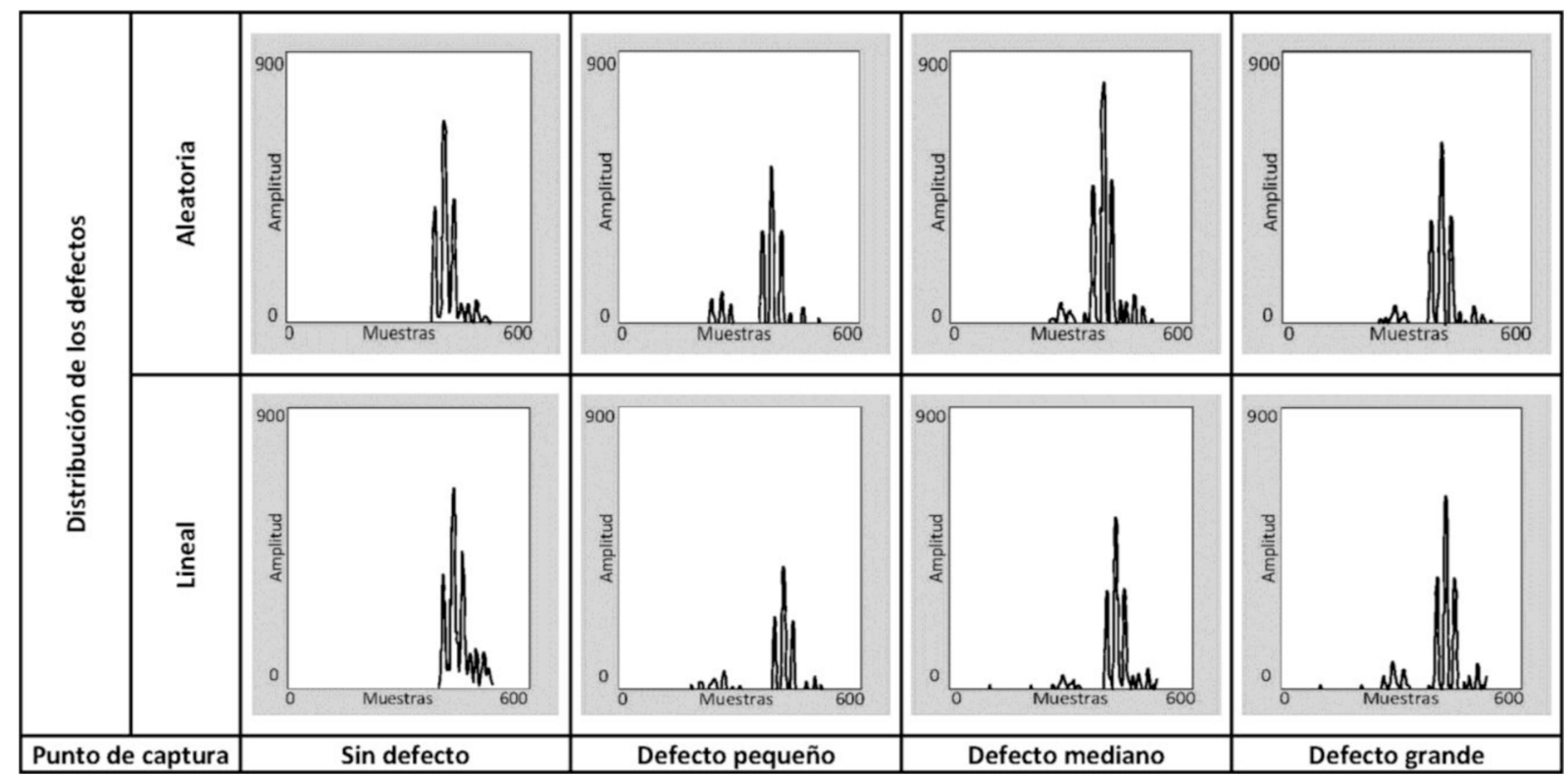

Figura 8. Señales ultrasónicas obtenidas en la probeta de $11 \mathrm{~mm}$ de espesor.
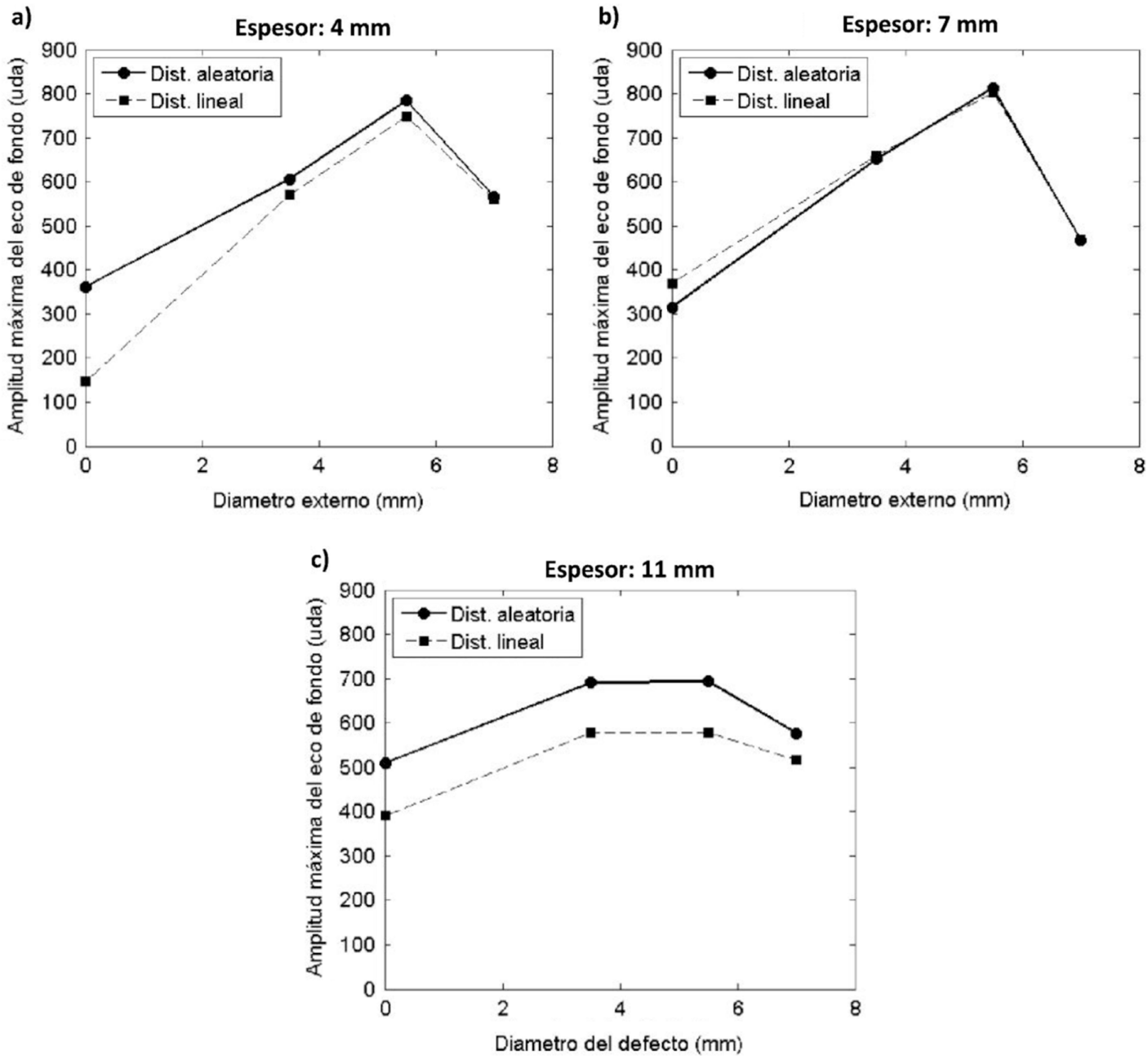

FIGURA 9. Amplitud máxima del ecopulso en función del diámetro externo de cada probeta considerada. 

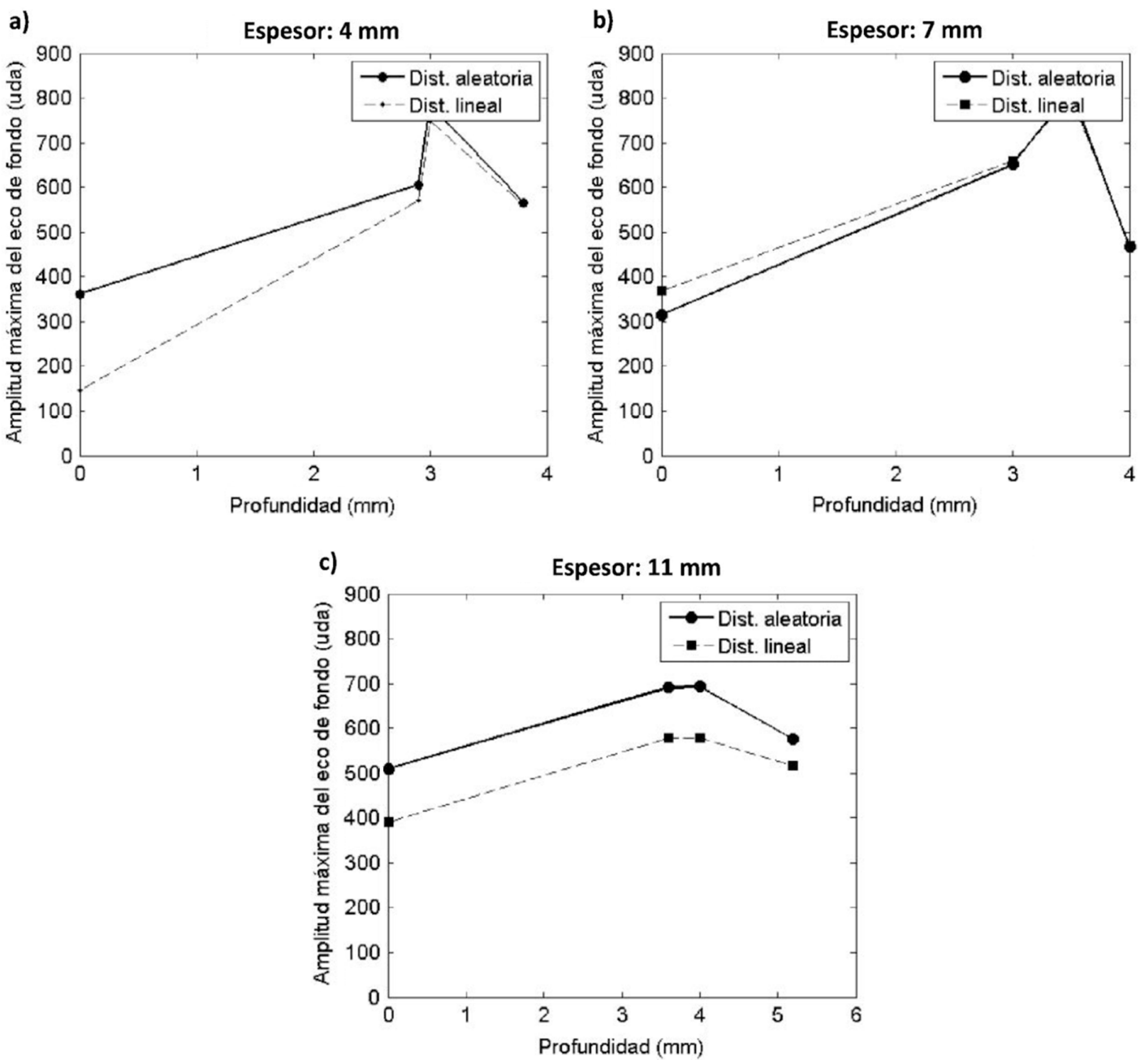

Figura 10. Amplitud máxima del ecopulso en función de la profundidad de la picadura de cada probeta considerada.

que tiene como objeto correlacionar los resultados obtenidos con las variables de estudio: el espesor de las probetas, el tamaño de las heterogeneidades y su posicionamiento en el material.

A continuación se representa cómo varía, para cada espesor considerado, la amplitud máxima del eco de fondo, tanto con el diámetro externo del defecto que simula la picadura en la superficie metálica, o defecto externo (Fig. 9), como con la profundidad de las mismas, defecto interno (Fig. 10), para intentar relacionar ambas variables. En primer lugar hay que resaltar de nuevo que no hay influencia apreciable en la distribución de los defectos; en segundo lugar se observa que, para los defectos generados en las probetas de 4 y $7 \mathrm{~mm}$ de espesor, la amplitud del eco de fondo alcanza un máximo próximo a 800 unidades de altura (uda). Esta tendencia no la siguen los defectos de mayor profundidad puesto que, pasados en ambos casos valores de defectos externos e internos, la tendencia es cuasi asintótica, ya que se obtienen valores prácticamente iguales; este hecho no es seguido por la señal producida en la probeta de $11 \mathrm{~mm}$ de espesor, ya que su tendencia es independiente de la distribución de las picaduras, pero con diferencias apreciables en el valor de la amplitud.

En la Figura 11 se representan los valores de la amplitud máxima del eco de fondo cuando varían las dimensiones de la picadura, es decir, su diámetro externo y su profundidad. En las Figuras 11a y 11b, correspondientes a las probetas de $4 \mathrm{~mm}$ y $7 \mathrm{~mm}$ de espesor respectivamente, se observa una fuerte dependencia entre las variables consideradas y el valor de la amplitud máxima del eco de fondo; el efecto más notable se obtiene cuando la profundidad del defecto es de $3 \mathrm{~mm}$ y el diámetro próximo a su valor máximo, $7 \mathrm{~mm}$. Para la probeta de $11 \mathrm{~mm}$, cuyo caso se representa en la Figura 11c, se observa una menor dependencia del valor de amplitud con respecto a la profundidad, puesto que está fundamentalmente influenciado por el valor del diámetro superficial del defecto así considerado, es decir, será la variable que gobierne la detección por esta técnica. 

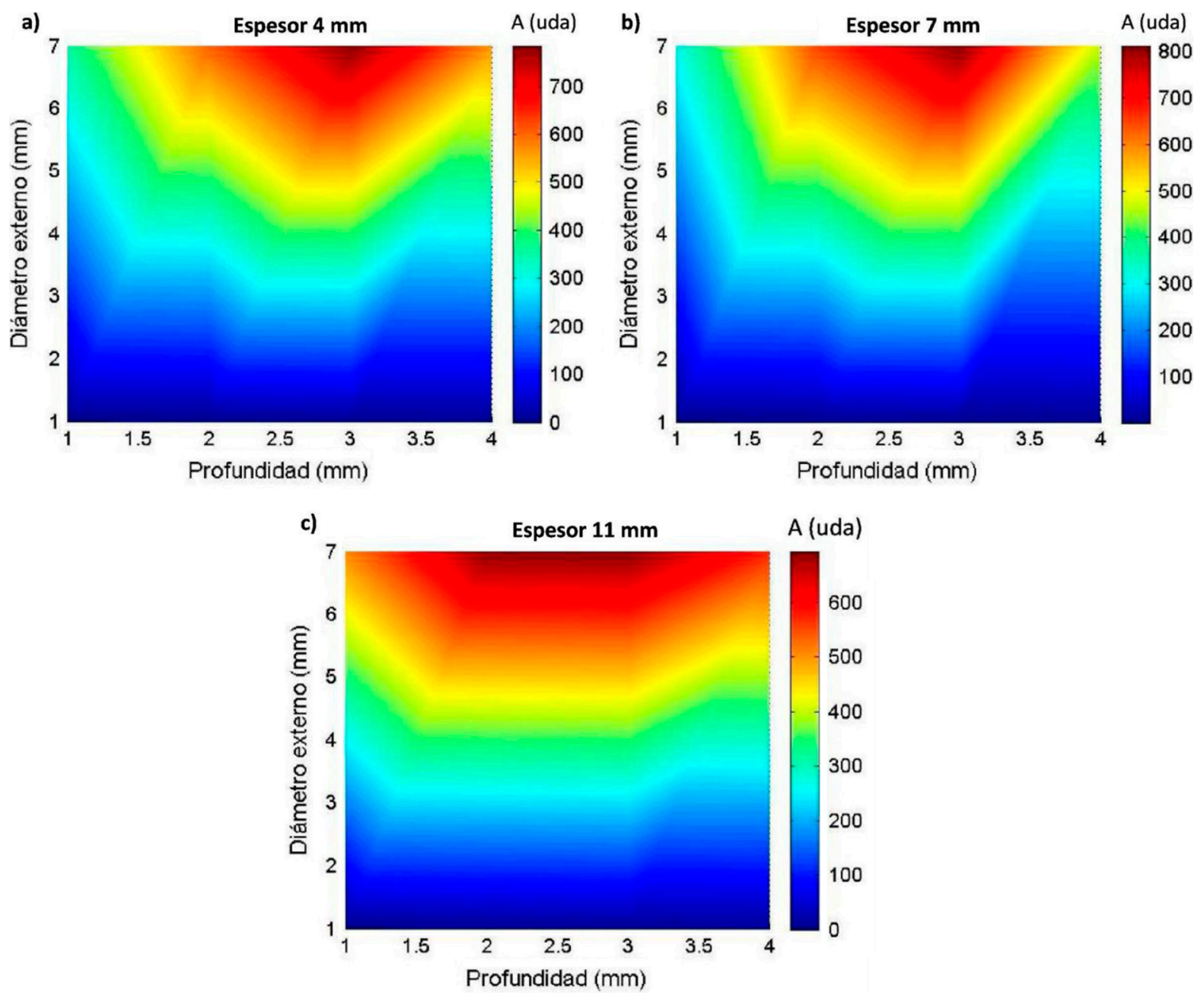

FIgURA 11. Relación Diámetro - Profundidad - Amplitud máxima

En conclusión, teniendo en cuenta que la fase inicial de una picadura comienza con la rotura de la capa pasiva del sistema metálico, los resultados obtenidos corroboran el hecho de que, para espesores pequeños de pieza a inspeccionar, quien gobierna el proceso es el valor de la profundidad del defecto, mientras que, a medida que aumenta su espesor, es el valor del diámetro externo del defecto el que se pudiera utilizar para determinar la existencia de la picadura mediante la inspección ultrasónica.

\section{CONCLUSIONES}

En este trabajo se han relacionado los parámetros ultrasónicos, amplitud de la onda, representada por su altura en la pantalla del equipo de inspección, o intensidad de propagación de la misma en el material en un determinado tiempo, para detectar la corrosión por picadura en aceros inoxidables, simulándolas con perforaciones de distinto diámetro y profundidad, tal y como las que presenta un material en servicio, lo que podría facilitar el diagnóstico in situ. Las conclusiones más relevantes del estudio son las siguientes:

- La inspección por ultrasonidos en piezas con defectos de geometría irregular, en particular cónicos, presenta gran complejidad para poder crear un patrón de referencia que facilite la detección de corrosión por picaduras ya que, al aumentar el diámetro del defecto, el ángulo inherente a la conicidad, altera el rebote del pulso.

- Las piezas de espesor pequeño permiten una adecuada y precisa detección de la profundidad de los defectos mientras que, en la pieza de mayor espesor, es el diámetro superficial el que condiciona el resultado de la inspección ultrasónica.

- Existe un mínimo efecto de la distribución de los defectos en la superficie de la pieza, lineal o aleatoria, tal y como se ha planteado en este estudio. 
- Se ha apreciado un fuerte efecto del estado superficial del material para poder desarrollar el patrón de detección de defectos, ya que ha habido probetas con protuberancias, debido al poco espesor de la probeta, o probetas con rugosidad superficial debido al mecanizado. En estos casos, los valores obtenidos nunca se podrían tomar como indicativos para interpretar la existencia de defectos en un material, por lo que habría que preparar superficialmente la pieza.

- El objetivo inicial del trabajo fue detectar, conocer las dimensiones de las picaduras y posicionar su ubicación en la superficie a inspeccionar, utilizando ultrasonidos y, mediante un estudio posterior, llegar a elaborar un patrón basado en los valores de la amplitud máxima del eco ultrasónico que ayudase a la caracterización de las mismas. Teniendo en cuenta los resultados obtenidos, comentados anteriormente, se puede concluir que la confección de dicho patrón es inviable.

\section{REFERENCIAS}

Antonya, P.J., Singh Raman, R.K., Raman, R., Kumar, P. 2010. Role of microstructure on corrosion of duplex stainless steel in presence of bacterial activity. Corros. Sci. 52 (4), 1404-1412. http://dx.doi.org/10.1016/j.corsci.2009.12.003.

ASTM G46 - 94, 2005. Standard Guide for Examination and Evaluation of Pitting Corrosion.

Bethencourt, M., García de Lomas, J.,Corzo, A., Villahermosa,D., Matres, V. 2010. Efecto de la biopelícula en la corrosión de aceros inoxidables. Rev. Metal. 46 (1), 37-51. http://dx.doi. org/10.3989/revmetalm.0910.

Biezma, M.V., Berlanga, C., Larrea, I. 2011. Estudio fractográfico de los aceros inoxidables dúplex UNS S32205 y UNS S32750 con distintos tratamientos térmicos. An. Mec. Fract. 28, 169-174.

Duret-Thual, C. 2011. Pitting and crevice corrosion - Basic mechanistic aspects for the selection and use of stainless steels. Matériaux \& Techniques 99 (81-91), 81-91. http:// dx.doi.org/10.1051/mattech/2011049

Fajardo, S., Bastidas, D.M., Ryan, M.P., Criado, M., McPhail, D.S., Bastidas, J.M. 2010. Low-Nickel Stainless Steel Passive Film in Simulated Concrete Pore Solution: A SIMS Study. Appl. Surf. Sci. 256 (21), 6139-6143. http://dx.doi. org/10.1016/j.apsusc.2010.03.140.

Garin, J.L., Manheim, R.L., Camus, M.A. 2010. Estudio sobre la disolución de fase sigma en un acero dúplex S31803. Rev. Latinoam. Metal. Mater. 30, 46-53.

Gosálbez, J., Salazar, A., Miralles, R., Bosch, I., Vergara, L. 2005. Mejora de la detección y caracterización de materiales con un sistema automático de ultrasonidos. Proc Symposium URSI2005, Gandia, España, Union RadioScientifique Internationale, Ghent, Bélgica, 1-4.

Hamzah, E., Hussain, M.Z., Ibrahim, Z., Abdolahi, A. 2013. Influence of Pseudomonas aeruginosa bacteria on corrosion resistance of 304 stainless steel. Corros. Eng. Sci. Technol. 48 (2), 116-120. http://dx.doi.org/10.1179/174327 8212Y.0000000052

Hastuty, S., Nishikata, A., Tsuru, T. 2010. Pitting corrosion of type 430 stainless steel under chloride solution droplet. Corros. Sci. 52 (6), 2035-2043. http://dx.doi.org/10.1016/j. corsci.2010.02.031.
Hinds, G., Wickström, L., Mingard, K., Turnbull, A. 2013. Impact of surface condition on sulphide stress corrosion cracking of 316L stainless steel. Corros. Sci. 71, 43-52. http://dx.doi.org/10.1016/j.corsci.2013.02.002.

Kim, S.-T., Jang, S.-H., Lee, In-S., Park, Y.-S. 2011. Effects of solution heat-treatment and nitrogen in shielding gas on the resistance to pitting corrosion of hyper duplex stainless steel welds. Corros. Sci. 53, 1939-1947. http://dx.doi. org/10.1016/j.corsci.2011.02.013.

Krautkrämer, J., Krautkrämer, H. 1990. Ultrasonic testing of materials. Springer-Verlag, Berlin.

Linhardt, P. 2010. Twenty years of experience with corrosion failures caused by manganese oxidizing microorganisms. Mater. Corros. 61 (12), 1034-1039. http://dx.doi. org/10.1002/maco.201005769.

Maier, B., Frankel, G.S. 2010. Pitting corrosion of bare stainless steel 304 under chloride solution droplets. J. Electrochem. Soc. 157 (10), C302-C312. http://dx.doi. org/10.1149/1.3467850.

Mirjalili, M., Momeni, M., Ebrahimi, N., Moayed, M.H. 2013. Comparative study on corrosion behaviour of Nitinol and stainless steel orthodontic wires in simulated saliva solution in presence of fluoride ions. Mater. Sci. Eng. C 33 (4), 2084-2093. http://dx.doi.org/10.1016/j. msec.2013.01.026.

Moreno, D.A., García, A.M., Ranninger, C., Molina, B. 2011. Corrosión por picaduras en depósitos de agua de acero inoxidable austenítico en trenes hotel. Rev. Metal. 47 (6), 497-506. http://dx.doi.org/10.3989/revmetalm.1146.

Orlikowski, J., Krakowiak, S. 2013. Pitting corrosion and stress-corrosion cracking of buffer tanks in a brewery. Eng. Fail. Anal. 29, 75-82. http://dx.doi.org/10.1016/j. engfailanal 2012.10.013.

Pardo, A., Otero, E., Merino, M.C., López, M.D., Utrilla, M.V. 2001. Estudio de la resistencia a la corrosión localizada del acero inoxidable superaustenítico $24,1 \mathrm{Cr} 22 \mathrm{Ni} 7,1 \mathrm{Mo}$ en mezclas que contienen iones cloruro y cloruro-fluoruro. Rev. Metal. 37, 499-508. http://dx.doi.org/10.3989/revmetalm.2001.v37.i4.515.

Rodríguez, C., Fernández, M Alonso, L. Pérez-Oria, J.M 2006. Sistema de detección automatizado de grietas en piezas de fundición mediante ultrasonidos y técnicas clásicas de reconocimiento. Proc XXVII Jornadas de Automática, Almería, España, CEA, Barcelona, España, 1-7.

Rodríguez, C. 2012. Sistema automatizado de detección de defectos en piezas metálicas mediante ensayos no destructivos con ultrasonidos. Tesis Doctoral, Escuela Superior de Ingenieros Industriales y de Telecomunicación, Universidad de Cantabria, España. ISBN: 978-84-616-1307-6.

Rodríguez, C., Biezma, M.V., Fernández, M. 2013. Characterization of sigma in duplex stainless steels using nondestructive techniques by ultrasounds. Mater. Test. 55 (6), 448-454. http://dx.doi.org/10.3139/120.110461

Sambath, S., Nagaraj, P., Selvakumar, N. 2011. Automatic defect classification in ultrasonic NDT using artificial intelligence. J. Nondestruct. Eval. 30 (1), 20-28. http://dx.doi. org/10.1007/s10921-010-0086-0.

Sandvik. www.sandvik.com.

Shivaraj, K., Wadhwan, R., Balasubramaniam, K., Krishnamurthy, C.V. 2008. Ultrasonic circumferential guided wave for pitting type corrosion imaging at inaccessible pipe support locations. J. Press. Vessel. Technol. 130 (2), 1-11. http://dx.doi.org/10.1115/1.2892031.

Szklarska-Smialowska, Z 1972. Influence of sulfide inclusions on pitting corrosion of steels. Corrosion 28 (10), 388-396. http://dx.doi.org/10.5006/0010-9312-28.10.388.

Tavares, S.S.M., Pardal, J.M., Ponzio, E., Loureiro, A., de Souza, J.A. 2010. Influence of microstructure on the corrosion resistance of hyperduplex stainless steel. Mater. Corros. 61 (4), 313-317. http://dx.doi.org/10.1002/maco.200905386. 